\title{
Produção acadêmica sobre dança nos periódicos nacionais de Educação Física
}

CDD. 20.ed. 793

796
Barbara MUGLIA-RODRIGUES* Walter Roberto CORREIA*
*Escola de Educação

Física e Esporte

Universidade de São Paulo.

\section{Resumo}

0 presente estudo visou identificar e analisar a produção do conhecimento relativo ao fenômeno dança no contexto dos periódicos científicos nacionais de Educação Física no período de 2000 a 2010 . Foram explorados títulos e resumos de artigos publicados em seis periódicos. Os artigos encontrados foram enquadrados em cinco categorias e os resultados obtidos foram: dos 2362 artigos publicados, $67(2,84 \%)$ abordaram dança. Desses, 38,81\% na área dos Estudos Socioculturais do Movimento Humano, 34,33\% na Pedagogia do Movimento Humano - dentre os quais, 65,22\% tratam do âmbito escolar -, 14,93\% na Biodinâmica do Movimento Humano e 5,97\% em cada uma das áreas Adaptação do Movimento Humano e Comportamento Motor. Esses resultados foram discutidos em relação à necessidade da elaboração de uma produção acadêmica que explore a multidimensionalidade do fenômeno dança em âmbitos inter e multidisciplinares, favorecendo uma aproximação acadêmica e profissional entre os protagonistas da Dança e da Educação Física.

Palavras-Chave: Estudos interdisciplinares; Dança; Educação física.

\section{Introdução}

A dança é um fenômeno polissêmico, ou seja, passível de múltiplas configurações sociais como, por exemplo, espetáculo, comunicação, ritualização, terapia, estilo de vida, exercício, entre outras possíveis significaçôes. Também pode ser compreendida como uma manifestação antropológica e artística e, hoje, é considerada uma área de conhecimento autônoma com cursos específicos de formação acadêmico-científica ${ }^{2,3}$ e profissional.

O filósofo Roger GaRaudy $y^{4}$ entende a dança como um modo de existir, de tal sorte que, a um só tempo, conhecimento, arte e religião compõem a dádiva e a celebração do viver. Para ele, dançar é antes de tudo, o estabelecimento de uma ativa relação entre homem e natureza, onde se vivencia e exprime com o máximo de intensidade essa relação com a natureza, com os deuses, com a sociedade e com o futuro, o que podemos identificar nas seguintes consideraçôes:
(...) Conhecer o já construído e produzido para depois buscar o que ainda não foi feito ${ }^{1}$.

\begin{abstract}
A dança é um modo de existir. Não apenas jogo, mas celebração, participação e não espetáculo, a dança está presa à magia e à religião, ao trabalho, à festa, ao amor e à morte. Os homens não sabem todos os momentos solenes de sua existência: A guerra e a paz, o casamento e os funerais, a semeadura e a colheita (p.13).
\end{abstract}

Enquanto uma das manifestações culturais mais antigas da história humana, não se sabe ao certo quando o ser humano dançou pela primeira vez. BOurCIER ${ }^{5}$ afirma que, "indiscutivelmente", o primeiro registro de ação de dança possui cerca de 14.000 anos e compunha um ato sagrado. Dessa forma, pode-se dizer que, desde a pré-história, a dança sempre esteve presente no mundo humano. Cada comunidade dançou e dança de uma forma diferente, com gestualidades e aspectos culturais muito específicos. Para GARAUDY "a dança não é apenas expressão e celebração da continuidade orgânica 
entre homem e natureza. É também realização da comunidade viva dos homens" (p.17).

A partir disso, pode-se considerar a dança uma manifestação construída histórica, social e culturalmente e caracterizá-la como um fenômeno de linguagem corporal artística reconhecido como campo de discussão das áreas das Artes e Humanidades, com marcantes distinçôes dos campos das Ciências do Esporte, da Educação Física, da Cinesiologia e outras áreas afins. No entanto, essa distinção não exclui a possibilidade de estudo e intervenção profissional acerca da dança nessas diversas áreas, visto que todos tratam do corpo em movimento.

Nesse sentido, DAOLIO ${ }^{6}$, que considera a cultura corporal de movimento objeto de estudo e atuação da Educação Física, explica que (p.3):

O profissional de educação física não atua sobre o corpo ou com o movimento em si (...). Ele trata do ser humano nas suas manifestações culturais relacionados ao corpo e ao movimento humanos, historicamente definidos como jogo, Esporte, dança, luta e ginástica. O que irá definir se uma ação corporal é digna de trato pedagógico pela educação física é a própria consideração e análise desta expressão na dinâmica cultural específica do contexto onde se realiza.

Assim sendo, como fenômeno cultural que se manifesta através e no corpo daquele que o experiência, o estudo, a pesquisa e a experiência da dança muito têm a contribuir para a atuação profissional, prática pedagógica e construção do conhecimento na área da Educação Física sobre as suas dimensões estética, artística e subjetiva do movimento, as quais normalmente são deixadas em segundo plano pelos seus cursos de preparação profissional.

Alguns autores ${ }^{2,7-8}$ acreditam que, na maioria dos cursos de graduação em Educação Física do Brasil, o tratamento dado ao fenômeno/tema dança é inadequado, superficial e impróprio, devido à redução da sua abrangência e do aprofundado enfoque biodinâmico, em detrimento dos saberes socioculturais e pedagógicos do movimento humano.

Considerando a autonomia das áreas Dança e Educação Física e as suas possíveis interfaces, pode-se visualizar essa relação sob duas perspectivas diferentes: o âmbito escolar e o não escolar.

No âmbito da Educação Física Escolar, encontram-se abordagens de ensino que buscam uma sistematização de seus conteúdos, como indicadas nas obras "Metodologia do Ensino da Educação Física", "Educação como Prática Corporal" 10 e "Transformação Didático-pedagógica do Esporte"11.
Além disso, há políticas educacionais registradas e oficializadas por documentos que proporcionam suportes norteadores para a atuação dos professores nas escolas, como: Parâmetros Curriculares $\mathrm{Na}$ cionais - $\mathrm{PCN}^{12}$; Referencial Curricular Nacional para a Educação Infantil - RCNEI ${ }^{13}$; e a Proposta Curricular do Estado de São Paulo ${ }^{14}$.

Tanto os autores que buscaram sistematizações, quanto as políticas educacionais acima, apresentam a importância do trabalho com dança e outras diversas manifestações da cultura corporal, como ginástica, jogo, esportes e lutas/artes marciais no âmbito do componente curricular Educação Física.

No entanto, ainda se vê nas escolas de hoje professores que escolhem aleatoriamente os conteúdos de suas aulas, o que normalmente se dá baseado na identificação pessoal que o docente tem com os temas ${ }^{15}$. Com frequência, os conteúdos escolhidos abarcam o fenômeno esportivo a ser trabalhado num modelo tecnicista, visando alcançar o melhor rendimento esportivo dos alunos. Segundo os autores, isso costuma acontecer em detrimento da consideração da cultura local de cada realidade e de um tratamento pedagógico das manifestaçōes corporais, inclusive do esporte.

No âmbito não escolar, dois documentos visam orientar e legitimar a atuação do profissional de Educação Física, são eles: as Diretrizes Curriculares Nacionais para os cursos de graduação em Educação Física - DCNEF ${ }^{16}$ - e o artigo $1^{\circ}$ da resolução $n^{\circ}$ 046/2002 do Conselho Federal de Educação Física ${ }^{17}$.

Os dois documentos entendem que a dança é uma das diversas manifestações de "atividade física". Sendo assim, um dos objetos de preparação e intervenção profissionais no âmbito da Educação Física, a partir da aplicação de conhecimentos de cunho científico, técnico e pedagógico na "perspectiva de um compromisso ético". Entretanto, segundo MiRANDA ${ }^{7}$, é possível identificar uma tendência dos profissionais e cursos de graduação em Educação Física assimilar a dança como exercício físico, deixando de lado os seus sentidos e significados durante todo o seu percurso construído na história da humanidade.

Dessa forma, esta pesquisa se desenvolveu basicamente a partir da premissa que concebe a Educação Física como profissão academicamente orientada ${ }^{18}$, o que pressupõe uma fundamentação para ação profissional.

Somando-se a esses argumentos, dispomos também de um mapeamento realizado por AQUINO ${ }^{19}$ acerca das pesquisas acadêmicas em dança no país, o qual se focou sobre teses e dissertações distribuídas em diversas áreas acadêmicas e concluiu que "a 
pesquisa em dança é uma prática recente com poucos exemplares".

O presente estudo tem por pretensão ampliar, ou até mesmo, estender a análise incorporando as produções provenientes dos periódicos nacionais de educação física, além de ilustrar as propensōes teóricas em determinadas áreas ou subáreas do campo da educação física e do movimento humano.

Assim sendo, este trabalho visou investigar a produção do conhecimento relativo ao fenômeno dança e suas especificidades na perspectiva das subáreas de estudo da educação física nos periódicos científicos nacionais.

\section{Método}

Foram analisados títulos e resumos de artigos referentes ao fenômeno/tema dança publicados em periódicos nacionais de Educação Física no período de 2000 a 2010 e elaborada uma classificação das temáticas relativas à natureza de cada trabalho.

Neste sentido, desde a busca em catálogos de produção das universidades em seus programas de pós-graduação até a publicação de artigos acadêmicos, há inúmeras possibilidades de levantamentos e mapeamentos de produção.

A eleição do referido período justifica-se pelo conjunto de transformações sociais no âmbito da educação face às implicações das políticas públicas desse decênio sobre o campo da educação básica e superior e suas repercussões para o período vindouro. Cabe aqui também destacar suas inexoráveis interfaces no tocante ao desenvolvimento científico e tecnológico impulsionado por instâncias de fomento e promoção da produção acadêmica.

No que tange ao recorte contextual das revistas nacionais de educação física, procurou-se como referência as sinalizaçôes legitimadoras provenientes de estudos semelhantes como, por exemplo, CORREIA e FrANCHI$\mathrm{N}^{20}$ e ANTUNES et al. ${ }^{21}$, além da notória representatividade social que o sistema Qualis/CAPESa tem para a comunidade acadêmica e para os domínios da política pública de ciência, tecnologia e capacitação de pessoal para o ensino superior. Com esse sistema, muitos dos cursos de pós-graduação mais bem avaliados - níveis 6 e 7 - reconhecem como de maior impacto em termos de produção de conhecimento os periódicos científicos classificados nos estratos A1, A2, B1 e B2.

A partir disso e com a finalidade de delimitar o universo explorado pelo estudo, os periódicos científicos analisados foram aqueles que se enquadravam na área 21 (Educação Física), se caracterizavam como nacionais e são classificados como de estrato A1, A2, B1 e B2 pelo Qualis, somando o total de seis periódicos: 1) Revista Motriz (UNESP/Rio Claro) - estrato B1; 2) Revista Movimento (UFRGS/Rio Grande do Sul) - estrato B1;3) Revista Brasileira de Ciências do
Esporte (Colégio Brasileiro de Ciências do Esporte CBCE) - estrato B2; 4) Revista Brasileira de Educação Física e Esporte (USP/São Paulo) - estrato B2; 5) Revista Brasileira de Ciência e Movimento (Centro de Estudos do Laboratório de Aptidão Física de São Caetano do Sul - CELAFISCS - e Universidade Católica de Brasília) - estrato B2; 6) Revista da Educação Física (UEM/Maringá) - estrato B2.

Foram analisados títulos e resumos de artigos presentes nos periódicos selecionados. Aqueles trabalhos cuja leitura do título e do resumo não foram suficientes para o entendimento de suas temática e objetivo, houve a leitura do texto completo, como também realizado no trabalho de ANGELUCCI et al. ${ }^{22}$, os quais deixaram bem clara a preocupação com o rigor científico.

Todos os artigos tiveram temáticas classificadas em "subáreas do conhecimento" da "Cinesiologia" e da "Educação Física", segundo a estrutura acadêmica apresentada por $\mathrm{TANI}^{23}$.

\section{A análise de títulos e resumos}

FERreira ${ }^{1}$ aponta que o título, o qual aparece no índice e no cabeçalho do artigo, deve trazer ao leitor a ideia principal sobre o conteúdo a ser discutido, a fim de informá-lo da existência do trabalho. Nessa perspectiva, ele explica que o resumo possui a finalidade de dar mais abrangência ao conteúdo que deve ser informado ao leitor de forma eficaz e eficiente, além de facilitar o acesso aos trabalhos cujas temáticas lhe interessem.

Assim sendo, é importante destacar que todos os resumos e títulos analisados passaram pelo crivo de uma avaliação acadêmico-científica criteriosa proferida pelos diferentes periódicos e seus respectivos pareceristas, conferindo a essa produção algum grau de rigorosidade epistemológica. Por meio dos títulos e resumos, foi possível inferir as temáticas dos artigos, as intencionalidades expressas pelos objetivos ali contidos, o que oferece condiçôes para uma caracterização delimitada e parcial dos estudos analisados. 


\section{Classificação dos artigos}

TANI ${ }^{23}$ propôs uma estrutura acadêmica que apresenta a Cinesiologia como área do conhecimento cujo objeto de estudo é o movimento humano, constituída por "três subáreas de investigação": 1) Biodinâmica do Movimento Humano - englobando a Biomecânica, a Cineantropometria, a Bioquímica do Exercício e a Fisiologia do Exercício; 2) Comportamento Motor - reunindo o Controle Motor, a Aprendizagem Motora, o Desenvolvimento Motor e a Psicologia do Esporte; e 3) Estudos Socioculturais do Movimento Humano - composto pela História, a Sociologia, a Antropologia, a Filosofia, a Ética e a Estética do Movimento Humano.

Dessa forma, o autor caracteriza a Cinesiologia como área de pesquisa básica, a qual subsidia a "pesquisa eminentemente aplicada" em Educação Física. Essa, por sua vez, é constituída por outras duas subáreas: 1) Pedagogia do Movimento Humano - caracterizada pelos estudos em Educação Física Escolar e sobre processo ensino-aprendizagem; e 2) Adaptação do Movimento Humano - composta por conhecimentos básicos para o "desenvolvimento de programas de Educação Física” para populaçōes com deficiências ou com demandas específicas relacionadas à saúde, como no caso de gestantes, asmáticos, cardiopatas, entre outros.

A estrutura acadêmica proposta foi utilizada para a classificação temática de cada um dos artigos, os quais tiveram títulos e resumos analisados e classificados entre as cinco categorias a seguir: 1) Biodinâmica do Movimento Humano, 2) Comportamento

\section{Resultados}

De um total de 2362 artigos publicados nos periódicos nacionais verificados, foi possível identificar a produção de $67(2,84 \%)$ artigos relativos ao fenômeno/tema Dança. A FIGURA 1 mostra a distribuição dessa produção entre os anos de 2000 a 2010. Pode-se observar que a porcentagem de produção sobre dança oscilou ao longo dos anos, sendo que o ano com menor porcentagem (2006)
Motor, 3) Estudos Socioculturais do Movimento Humano, 4) Pedagogia do Movimento Humano e 5) Adaptação do Movimento Humano.

É importante mencionar que a utilização dessa estrutura não é consensual, mas fruto de embates epistemológicos distintos ${ }^{24}$. No entanto, para efeito desse estudo, a respectiva classificação permite uma localização de áreas e territórios preponderantes e atualizados no campo acadêmico e profissional da Educação Física - como também realizada no estudo de CORREIA e FRANCHINI ${ }^{20}$ acerca dos artigos publicados sobre o fenômeno/tema Lutas, Artes Marciais e esportes de combate. Como evidência desse dissenso, pode-se verificar que não há uma área denominada "Cinesiologia" dentre o conjunto de áreas de pesquisa estabelecidas pela CAPES, há apenas "Educação Física" entre as áreas das ciências da saúde.

Não se pretende aqui discutir a fundo a nomenclatura da área de conhecimento, visto que isso traria margem a muita discussão e argumentações. No entanto, ainda que pautados no entendimento da "Educação Física" enquanto área de ciência aplicada e prática pedagógica ${ }^{23}$, esse termo será utilizado como costuma ser consagrado socialmente pelo uso, referindo-se a uma área do conhecimento - incluindo os conhecimentos da "Cinesiologia" - e de intervenção profissional.

Hoje, essa classificação reflete áreas de suporte tanto no âmbito profissional, quanto no acadêmico e de reconhecimento por parte dos protagonistas da área. Assim, entende-se que a utilização da referida estrutura favorece de maneira eficaz o mapeamento e classificação das publicações.

foi subsequente àquele de maior porcentagem de produção (2005).

Com relação à distribuição dessa produção em relação às subáreas do conhecimento, a TABELA 1 permite verificar que Estudos Socioculturais do Movimento Humano e Pedagogia do Movimento Humano fora aquelas com maior produção ao longo de 2000 a 2010 


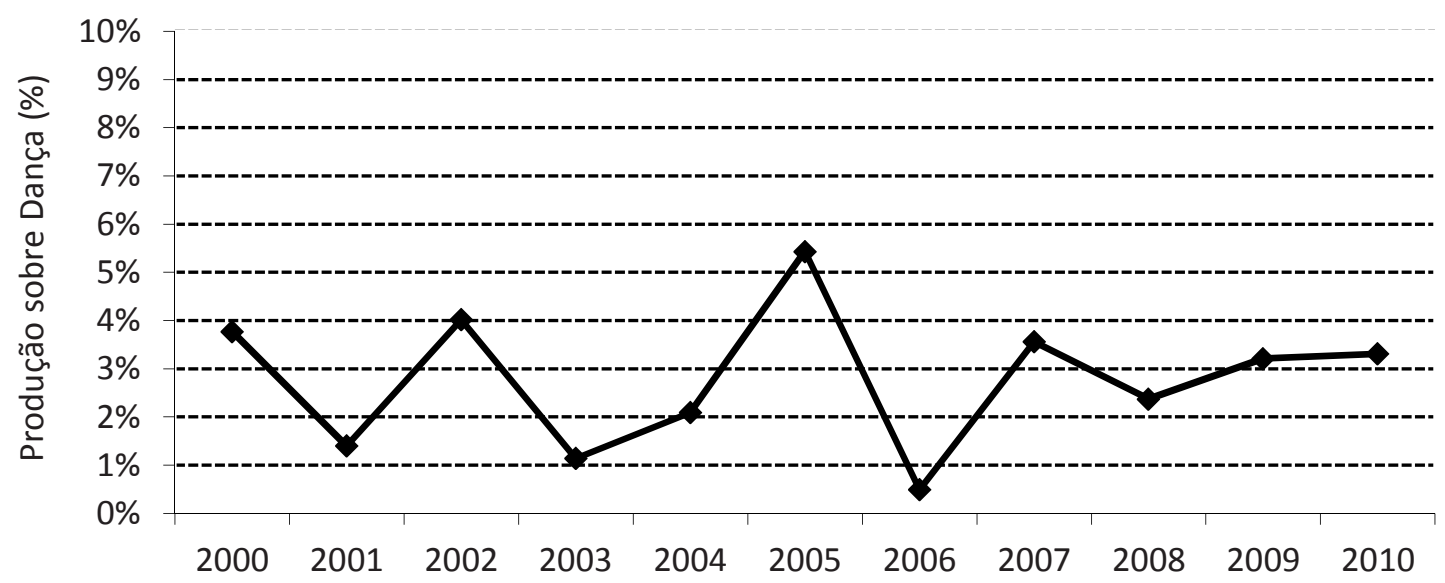

FIGURA 1 - Produção sobre dança (\%) de 2000 a 2010.

TABELA 1 - Distribuição dos artigos (\%) sobre dança encontrados em relação a cada subárea do conhecimento entre os anos 2000 e 2010.

\begin{tabular}{lccccccccccc}
\hline Subárea & $\mathbf{2 0 0 0}$ & $\mathbf{2 0 0 1}$ & $\mathbf{2 0 0 2}$ & $\mathbf{2 0 0 3}$ & $\mathbf{2 0 0 4}$ & $\mathbf{2 0 0 5}$ & $\mathbf{2 0 0 6}$ & $\mathbf{2 0 0 7}$ & $\mathbf{2 0 0 8}$ & $\mathbf{2 0 0 9}$ & $\mathbf{2 0 1 0}$ \\
\hline Estudos socioculturais do movimento humano & 25 & 0 & 29 & 50 & 50 & 60 & 100 & 50 & 33 & 36 & 25 \\
Pedagogia do movimento humano & 25 & 50 & 43 & 0 & 0 & 20 & 0 & 50 & 17 & 55 & 42 \\
Biodinâmica do movimento humano & 25 & 50 & 29 & 50 & 25 & 10 & 0 & 0 & 50 & 0 & 0 \\
Comportamento motor & 25 & 0 & 0 & 0 & 0 & 0 & 0 & 0 & 0 & 0 & 25 \\
Adaptaçáo do movimento humano & 0 & 0 & 0 & 0 & 25 & 10 & 0 & 0 & 0 & 9 & 8 \\
\hline
\end{tabular}

Abaixo, será apresentada a localização de artigos sobre dança em cada um dos periódicos "mapeados" e suas devidas classificações quanto às subáreas do conhecimento. Não temos, com isso, a intenção de ranquear os periódicos, mas - enquanto dados complementares aos objetivos deste estudo -, eles nos permitem vislumbrar algumas tendências acadêmicas específicas a cada um deles.

A revista Movimento apresentou, dentre os seis periódicos, a maior porcentagem de artigos acerca da dança (5,62\%). É interessante observar maior incidência das pesquisas nas subáreas de Estudos Socioculturais do Movimento Humano (57,89\%), seguida da subárea de Pedagogia do Movimento Humano (36,84\% - desses, 57,14\% de artigos no âmbito escolar), um artigo $(5,26 \%)$ na subárea de Comportamento Motor e a ausência de artigos em Adaptação do Movimento Humano e Biodinâmica do Movimento Humano.

Na revista Motriz, foi encontrada a segunda maior porcentagem de artigos relacionados à dança $(5,44 \%)$ e, dentre eles, a predominância de publicaçôes foi sobre as áreas de Pedagogia do Movimento Humano (47,37\% - desses, 66,67\% no âmbito escolar) e Estudos Socioculturais do Movimento Humano (42,11\%). Houve também um artigo em cada uma das subáreas de Biodinâmica do Movimento Humano (5,26\%) e Comportamento Motor $(5,26 \%)$ e nenhum na subárea de Adaptação do Movimento Humano.

A terceira revista com maior porcentagem de artigos sobre dança foi a Revista da Educação Físical $\operatorname{UEM}(2,95 \%)$. No entanto, ao contrário das revistas Motriz e Movimento, a sua considerável inclinação foi sobre publicações na subárea de Biodinâmica do Movimento Humano (54,55\%), seguida de Estudos Socioculturais do Movimento Humano (36,36\%), um artigo na Pedagogia do Movimento Humano $(9,09 \%)$ acerca da dança no âmbito escolar e nenhum artigo nas subáreas Comportamento Motor e Adaptação do Movimento Humano.

A Revista Brasileira de Ciências do Esporte apresentou 2,09\% de publicações envolvendo o tema dança, sendo sua predominância na subárea da Pedagogia do Movimento Humano (62,50\% - desses, $60 \%$ no âmbito escolar), seguida dos Estudos Socioculturais do Movimento Humano (37,50\%), não apresentando trabalhos publicados nas outras subáreas.

A Revista Brasileira de Ciência e Movimento publicou $1,51 \%$ dos artigos encontrados sobre o tema dança no período estudado, dentre os quais $50 \%$ pertencem à subárea Adaptação do Movimento Humano, 25\% a Comportamento Motor e o 
restante distribuído igualmente entre Biodinâmica do Movimento Humano (12,5\%), Pedagogia do Movimento Humano (12,5\% - todos relativos ao âmbito escolar da Educação Física) e nenhum em Estudos Socioculturais do Movimento Humano.

\section{Discussão}

Considerando o recorte específico dos periódicos investigados, os resultados da pesquisa podem sinalizar certas propensões da produção de conhecimento identificadas às subáreas articuladas aos domínios da Educação Física, bem como apontar para as demandas prementes de investimento científico em relação ao fenômeno/tema dança.

A partir dos dados apresentados, foi possível perceber leve predominância de artigos na subárea dos Estudos Socioculturais do Movimento Humano $(38,81 \%)$ sobre as outras subáreas, como Pedagogia do Movimento Humano (34,33\%), Biodinâmica do Movimento Humano (14,93\%), Adaptação do Movimento Humano (5,97\%) e Comportamento Motor (5,97\%).

O estudo nos sugere uma relativa restrição da produção de conhecimento acerca do fenômeno/ tema dança e, até mesmo, uma apropriação acadêmica parcial pela Educação Física. É importante ressaltar que esses dados, em virtude do próprio "recorte", não nos autorizam a efetuar uma generalização. Entretanto, ainda que de forma delimitada, os dados nos impelem a estabelecer uma problematização pertinente.

Face à multidimensionalidade do fenômeno, a suas esferas constitutivas (históricas, sociológicas, psicológicas. antropológicas, econômicas, semióticas, biológicas, etc.) são abordadas de forma desigual na perspectiva do conhecimento sistematizado. Somando-se a essas questôes, se faz necessária uma conjugação efetiva dessa mesma multidimensionalidade para compor o espectro de saberes e habilidades previstas no âmbito da integração e assimilação dos processos de formação e da atuação profissional em educação física. Associado a esse fato, inclui-se a problemática dessa produção em relação à coerência epistemológica da área da Educação Física. A título de exemplificação, a área dos Estudos Socioculturais do Movimento Humano tende a se apropriar da dança de forma a se circunscrever mais aos interesses das áreas científicas das humanidades do que a apreender o fenômeno (dança) na perspectiva da especificidade da Educação Física.
A Revista Brasileira de Educação Física e Esporte, antiga Revista Paulista de Educação Física/USP, publicou apenas $0,74 \%$ dos artigos encontrados sobre o fenômeno/tema dança, todos enquadrados na subárea Biodinâmica do Movimento Humano.

Outro exemplo relevante é o âmbito da Pedagogia do Movimento, no qual houve uma inclinação para abordagem da dança na perspectiva da educação física escolar $(66,22 \%)$ quando comparada ao domínio não escolar (33,78\%). Nesse aspecto, podemos conjecturar a necessidade de ampliação e diversificação do estudo da dança sob o enfoque da intervenção pedagógica nos diversos espaços e contextos educacionais por onde o fenômeno se configura de forma mais premente. No tocante aos domínios da educação formal, cabe a problematização dos fatores ou critérios para consubstanciar a dança como tema pertinente aos saberes escolares referentes ao componente curricular educação física. Essa temática é crucial na medida em que se faz necessária uma aproximação entre os docentes da educação básica, suas correspondentes demandas profissionais e os objetos de estudo e desejo dos pesquisadores.

Sob o enfoque biodinâmico, é preciso considerar a possibilidade de um maior investimento do ponto de vista das condicionantes estruturais e funcionais do movimento do corpo humano na dança, no sentido de prover os profissionais com subsídios teóricos, seja na ótica da biomecânica e da fisiologia, seja na do comportamento motor e da adaptação do movimento. A respeito deste último, entre uma composição ampla de possibilidades, essa temática pode ser alicerçada pela questão de processos de inclusão social frente à múltipla variedade de protagonistas que atuam direta ou indiretamente na vitalização do fenômeno dança. A precarização dos saberes biodinâmicos não contribui para a sustentação de práticas mais autônomas em relação à referida manifestação antropológica dança. Ainda sobre este item, considerar essa e as outras dimensôes de forma mais plural pode contribuir para a superação de um viés marcado pela "sociologismo" e "ideologismo" das manifestaçôes da cultura corporal e, inclui-se nesse contexto, a dança e o seu movimento.

De forma análoga e guardadas as devidas diferenciações e especificidades, este trabalho corrobora com as indicaçōes de CHRISTINA ${ }^{25}$, na área de aprendizagem motora, e de BRESSAN ${ }^{26}$, na educação física de forma geral, ao perceber que as pesquisas 
aplicadas em Educação Física acerca do fenômeno/ tema dança ainda são bastante escassas. A produção de conhecimento analisada nesse empreendimento investigativo não nos permite afirmar que a Educação Física tenha disposto para si um conhecimento orientado para captar, ou até mesmo, se aproximar do dinamismo que a pluralidade e diversidade cultural inexorável ao fenômeno dança comporta.

Sendo assim, entendemos que é imperiosa uma aproximação acadêmica e profissional entre os atores e autores dos âmbitos acadêmicos Dança e Educação Física e outros interlocutores possíveis na perspectiva de uma produção de conhecimento inter e transdisciplinar, além de um investimento oportuno e necessário de saberes para e pela intervenção profissional.

A partir da verificação de um recorte da produção de conhecimento em periódicos científicos nacionais da Educação Física, pôde-se perceber evidentes restrições quanto ao estudo do fenômeno dança na referida área. Dessa maneira, as limitações quantitativas e qualitativas da produção nacional circunscrita nos periódicos analisados não permitem o apontamento do fenômeno dança como algo que deva ser reservado em termos de exclusividade aos domínios do exercício profissional e acadêmico da Educação Física.

A polissemia - ou seja, a multiplicidade de significados - e a polifonia - os diversos anúncios - do fenômeno dança pelos múltiplos protagonistas sociais exigem que ela seja apropriada para além dos limites do conceito de exercício físico tão decorrente nos domínios acadêmicos e profissionais da Educação
Física, alcançando a compreensão da dança como um fenômeno sociocultural relevante em seu contexto e não negligenciando suas dimensōes artísticas, simbólicas, estéticas e ritualísticas.

Portanto, de maneira não menos importante, a partir das limitações dos conhecimentos produzidos, não identificamos razões que justifiquem os apelos corporativamente interessados para a subordinação acadêmica e profissional da dança e seu controle pela educação física. Assim, o potencial epistemológico e profissional que a Dança oferece à Educação Física são fundamentais para uma apropriação mais aprofundada e legítima desse fenômeno nos âmbitos da formação e atuação de professores, pesquisadores e profissionais da área.

A questão que aqui se coloca indaga a compatibilidade de uma ação profissional academicamente orientada com uma produção limitada do ponto de vista da diversidade temática e epistemológica que gravita e constitui o fenômeno dança e a própria Educação Física. Essa suposta precariedade pode restringir não apenas uma conceituação ampla do fenômeno, mas enseja uma visão "míope" do corpo e do movimento subtraindo o potencial de exploração socioeducativo (desenvolvimento humano em sua totalidade) da dança a partir dos interesses da Educaçãoo Física. Ainda nesse contexto, uma das possíveis e hipotéticas resultantes dessa precariedade de entendimento e compreensão do fenômeno nas suas relações com a Educação Física está na inerente perda da riqueza polissêmica que se assenta nas raízes e nas pulsões de movimento do ser humano na sua dimensão "dançante".

\title{
Notas
}

a. Conjunto de procedimentos utilizados para a estratificação de qualidade de produção intelectual dos programas de pósgraduação da Coordenação de Aperfeiçoamento de Pessoal de Nível Superior - CAPES.

\begin{abstract}
Production of knowledge on dance in Brazilian Physical Education journals

The present study aims to identify and analyze the production of knowledge related to the dance phenomenon in the context of the national scientific Physical Education journals throughout a 10-year period (2000 to 2010). Titles and summaries of articles published in six journals were explored. The articles found were grouped in Five categories and the results were: from the 2362 published articles, 67 $(2.84 \%)$ were related to dance. From these, $38.81 \%$ were about Human Movement Socio-cultural Studies,
\end{abstract}


34.33\% about Human Movement Pedagogy - among witch 65.22\% were related to school -, 17.93\% about Human Movement Biodynamic and 5.97\% in each areas Human Movement Adaptation and Motor Behavior. These data were discussed in relation to the need of elaborating an academic production that explores the multidimensionality of the dance phenomenon in inter-and multidisciplinary areas, favoring an academic and professional approach among the protagonists of Dance and of Physical Education.

KEY WORDS: Interdisciplinary studies; Dance; Physical education.

\section{Referências}

1. Ferreira NSA. Pesquisas denominadas "estado da arte": possibilidades e limites. Educação e Sociedade. 2002;23:257-72.

2. Morandi C. O descompasso da dança e da educação física. In: Strazzacappa M, Morandi C. Entre a arte e a docência: a formação do artista da dança. Campinas: Papirus; 2006.

3. Strazzacappa M. Dança na educação: discutindo questóes básicas e polêmicas. In: Strazzacappa M, Morandi C. Entre a arte e a docência: a formação do artista da dança. Campinas: Papirus; 2006.

4. Garaudy R. Dançar a vida. Rio de Janeiro: Nova Fronteira; 1980.

5. Bourcier P. História da dança no Ocidente. 2a ed. Appenzeller M, tradutora. São Paulo: Martins Fontes; 2001.

6. Daolio J. Educação física e o conceito de cultura. Campinas: Autores Associados; 2004.

7. Miranda M. A dança como conteúdo específico e como área de estudo no ensino superior [Dissertação]. São Paulo(SP):Universidade de São Paulo, Escola de Educação Física e Esporte; 1991.

8. Pacheco A. Educação física e dança: uma análise bibliográfica. Pensar a Prática. 1999;2:156-71.

9. Soares C, Taffarel C, Varjal E, Castellani Filho L, Escobar M, Bracht V. Metodologia do ensino de educação física. São Paulo: Cortez; 1992.

10. Freire J, Scaglia A. Educação como prática corporal. São Paulo: Scipione; 2003.

11. Kunz E. Transformação didático-pedagógica do esporte. 7 ed. Ijuí: Unijui; 2006.

12. Brasil. Secretaria de Educação Fundamental. Parâmetros curriculares nacionais. Brasília: Ministério da Educação; 1997.

13. Brasil. Secretaria de Educação Infantil. Referencial curricular nacional para a educação infantil. Brasília: Ministério da Educação; 1998.

14. São Paulo. Secretaria de Educação do Estado de São Paulo. Proposta curricular do Estado de São Paulo: educação física. São Paulo: SE/CENP; 2008.

15. Neira M, Nunes M. Pedagogia da cultura corporal: crítica e alternativas. São Paulo: Phorte; 2006.

16. Brasil. Ministério da Educação. Diretrizes curriculares nacionais para os cursos de graduação em educação física. Resolução CNE/CES no 7, de 4 de outubro de 2007. Disponível em: http://portal.mec.gov.br/cne/arquivos/pdf/2007/ rces007_07.pdf.

17. Conselho Federal de Educação Física. Documento de intervenção do profissional de educação física: Resolução no 046/2002. Rio de Janeiro: CONFEF; 2002.

18. Oliveira JGM, Betti M. Educação física e o ensino de primeiro grau: uma abordagem crítica. São Paulo: EPU/EDUSP; 1988.

19. Aquino R. A produção de pesquisas acadêmicas em dança no país: um olhar a partir de teses e dissertações. In: V Congresso ABRACE: criação e reflexão crítica; 2008, Belo Horizonte. Disponível em: http://www.portalabrace.org/ vcongresso/textosdancacorpo.html.

20. Correia WR, Franchini E. Produção acadêmica em lutas, artes marciais e esportes de combate. Motriz. 2010;16:1-9.

21. Antunes F, Dantas L, Bigotti S, et al. Um retrato da pesquisa brasileira em educação física escolar: 1999-2003. Motriz. 2005;11:179-84.

22. Angelucci C, Kalmus J, Paparelli R, Patto M. O estado da arte da pesquisa sobre o fracasso escolar (1991-2002): um estudo introdutório. Educação e Pesquisa. 2004;30:51-72.

23. Tani G. Cinesiologia, educação física e esporte: ordem imanente do caos na estrutura acadêmica. Motus Corporis. 1996;3:9-49.

24. Bracht V. Educação física \& ciência: cenas de um casamento (in)feliz. 2 ed. Ijuí: Unijuí; 2003.

25. Christina R. Whatever happened to applied research in motor learning? In: Skinner JS. et al., editors. Future directions in exercise and sport science research. Champaign: Human Kinetics; 1989.

98 • Rev Bras Educ Fís Esporte, (São Paulo) 2013 Jan-Mar;27(1):91-99 
26. Bressan ES. 2001: the profession is dead - was it murder or suicide? Quest. 1979;31:77-82.

ENDEREÇO

Walter Roberto Correia Escola de Educação Física e Esporte - USP Av. Prof. Mello Moraes, 65 05508-030 - São Paulo - SP - BRASIL e-mail: wr.correia@usp.br
Recebido para publicação: 19/08/2012

1a. Revisão: 11/05/2012

2a. Revisão: 29/05/2012

Aceito: 30/07/2012 